\title{
EducationandScience
}

Vol 41 (2016) No 184 311-331

\section{Academic Freedom from the Perspectives of Academics and Students: A Qualitative Study}

\author{
Didem Doğan ${ }^{1}$
}

\begin{abstract}
Academic freedom, which is the pre-condition of a stress-free academic life, has become a culture in democratic societies. The principles of equality, individuality and independence considerably shape our understanding and expectations of academic freedom. In addition to beinggenerally theoretical, studies on academic freedom focus on the restrictions on academic freedom experienced in the past. Thus, there is a need for a study that presentsproblems concerning academic freedom in detail and examines the views of students as well. The aim of this study is to reveal the views on academic freedom of academics and students studying at higher education institutions. In this study, 11 academics have been interviewed personally and the views of 298 studentson academic freedom in higher education institutions have been sought.

The views of the academics and students on academic freedom were grouped into six different categories: (1) freedom in education, (2) freedom in research, (3) freedom of speech, (4) institutional freedom, (5) the importance of academic freedom, and (6) the protection of academic freedom. As the result of the findings of the study, it can be said that academics and students are afraid of the negative reactions from the majority about their religious or political ideas. Students cannot express their ideas during classdue to the fear of being misunderstood or receiving a negative reaction. The same situation is observed within the relationshipsthat academics have with the administration. Academics have expressed that they have serious problems concerning academic freedom, and students have expressed that they do not feel free enough in university settings.
\end{abstract}

Keywords

DOI: 10.15390/EB.2016.6135

\section{Introduction}

In its main meaning, academic freedom, which is a modern term for an old idea, is the right of academics to perform their functions without any pressure by or fear of state officials or another authority (UNESCO, 1997, pp. 25-32). The freedom of academics, who conduct scientific research, is of great importance so that they are never under pressure from any authority due to the results that they

\footnotetext{
${ }^{1}$ Aksaray University, Faculty of Education, Department of Educational Sciences, Turkey, didemdogan@aksaray.edu.tr
} 
achieve, for scientific development and advancement, and for civilisation to reach higher levels (Dinler, 2013, p. 240).

Today, the existence in the world of many higher education institutions that have different policies has caused the occurrence of different definitions and applications of academic freedom. Thus, it is important to well comprehend the assumptions that underlie the epistemological foundations of academic freedom that are flexible and open to interpretation. Academic freedom is based on pragmatist rules of classical theories of freedom and freedom of thought and human rights. Thus, the principles of equality, individuality and independence considerably shape our understanding and expectations of academic freedom (Kahn \&Pavlich, 2000, p. 39).

In its common meaning, the concept of academic freedom, which is based on freedom of expression, is academics' and students' being able to express themselves freely (Roche, 1969; Dworking, 1979; Moran, 1998, p. 6; Diekema, 2000; Lynch, 2003; Frimpong, 2004; Gerstmann \& Streb, 2006; American Association of University Professors, 2006; Hayes, 2014). In this meaning, what makes academic freedom different is its being a type of freedom that is indigenousto academics and students (Anderson, 1934; Emerson \& Haber, 1964, p. 525; Searle, 1972, p. 175; UNESCO, 1998).

Scientists tackle academic freedom, which requires loyalty to the truth at the cost of drawing the reactions of others when necessary (Kennedy, 1998), in two aspects. These can be defined as universities' being independent of external control and academics' being free in performing their research and teaching. The independence of higher education institutions from external control is based on the necessity of universities to have rights that are specific to them and is closely related to university autonomy (Horn, 1999, pp. 309-349). Without academic freedom, which is a reflection of university autonomy, it is not possible to reach the desired goals in university education, science, and research (Woodhouse, 2009, p. 39).

Within the scope of academic freedom, there are freedoms given by scientific institutions and states to protect academics academically and professionally and to extend science, in addition to freedoms that academics must have as individuals. Therefore, academic freedom not only is a scientific vision or a moral issue but is also closely related to institutional guaranty. In this context, academic freedom can be defined as the guaranty of the need for protection, which is necessary for academics to be able to maintain their academic lives. From this perspective, academic freedom, which is the precondition of a carefree academic life (Verlag, 1998), provides the necessary conditions for the free pursuit of information (Borhan, 2009, p. 8). Hence, in each phase of academics' studies, we confront academic freedom, which is very comprehensive, from academics' teaching-learning activities to the research and publication of the results that they achieve.

\section{Academic Freedom in Turkey}

It is necessary to examine the constitutions of 1924, 1961, and 1982 in terms of academic freedom to evaluate academic freedom in the higher education institutions of Turkey. Although there was no phrase about universities in the 1924 constitution, many laws that would damage academic freedom were accepted until 1964. Having been intensely discussed in the 1961 constitution, article 120 accorded comprehensive rights to academics with regard to their academic freedom; however, the relevant article was changed in 1971, and many of these given rights were limited. The legal basis of academic freedom was determined in the 1982 constitution; nevertheless, different limitations were applied to academic freedom that were restricted in the 1961 constitution. Conducting research to reveal academic freedom in Turkey, Weiker (1962) made important observations about the issue. According to Weiker (1962), perhaps the most important factor that would provide academic freedom in Turkey would be separation of politics from universities. The direct active partisanship capacity of academics in Turkey is higher than that of their colleagues at similar universities in terms of development. In addition, academic freedom is very limited in Turkey. Universities force their members to comply with the standards concerning what the priorities of academic freedom accepted 
by the West should be or should not be (Weiker, 1962, p. 293). Weiker's study enlightens the period of higher education institutions in Turkey, which was approximately forty-three years ago.

When the recent history of Turkey is examined, it is understood that the universities' past, which has tried to survive despite the blows to their democracies and which are directly affected by these offences, is full of many violations and restrictions. The political, economic and social problems between 1973 and 1981 can be said to have hindered the constitution of the environment suitable for the development of academic freedom at universities. (Seggie \& Gökbel, 2015, p. 9). According to Summak's (1998) research on academics (N=204) in Turkey, 10 percent of them state that they did not have any idea about academic freedom. This study reveals that academics were dissatisfied with academic freedom in Turkey. According to Özipek (2001, pp. 13-14), academic freedom is irregular, changeable and inadequate in Turkey. Academic freedom has never become as it should be because of military coups and political instability in Turkey (Summak, 1998, p. 36). The structure of the system of higher education in Turkey (Eser\&Birkan, 2005, pp. 75-101) and academic freedom's suffering under law number 2547 can be shown as the reason for this. According to Doğan's (2015) study, which was conducted with over 790 academics, academic freedom is very limited in Turkey, and academics abstain from expressing their opinions freely.

Studies show that there are some problems concerning academic freedom, and these studies generally focus on academics. Meanwhile, the views of students, who are an important part of academic freedom, are typically ignored. Thus, there is a need for a study that presents the problems concerning academic freedom in detail and that examines the views of students as well. The aim of this study is to reveal the views concerning academic freedom of academics and students studying at higher education institutions.

\section{Method}

This research is a qualitative case study that examines a current case in its real-life context (Merriam, 2013). The main reason for determining the research method as qualitative is to obtain detailed information on academic freedom. Thus, two different interview forms that present the views of both academics and students have been used. The interviews conducted with the academics were held in Turkish. During the translation of the interviews, two experts in the English language were asked to translate the interviews directly to completely reflect the views of the participants. Small differences found in the translations of the experts were eliminated after the experts came together and reached a consensus.

The data were gathered using the interview technique. Prepared to reveal the views concerning academic freedom of students studying at higher education institutions and academics, two different interview forms consisting of structured questions were used in this research. Voice records of the interviews, which were conducted face to face with academics, were obtained; moreover, the students reported their opinions in a written manner. Content analysis was applied to the data that were acquired from the interviews.

Content analysis began with the views of the academics, who are among the important elements of academic freedom, concerning academic freedom, and this analysis constituted the foundation of the findings of this study because it was understood during the analysis of the data that the data gathered from the academics were very comprehensive. The data gathered from the academics constituted the foundation of the six conceptual categories of the qualitative research. At the second stage of the content analysis, the data gathered from the students were analysed. As the result of the analysis, it was understood that the data gathered from the students supported the data gathered from the academics. 


\section{Participants}

The interviews were conducted with academics employed by different universities and having different titles and experiences; then, these interviews were recorded. The interviews were maintained until the data repeated. In accordance with the literature, the interviews ended when no new information was acquired (Merriam, 2013). With this method, it is believed that 11 academics were enough for the sample of the study. A form consisting of open-ended questions on academic freedom was applied to students $(\mathrm{N}=298)$ who are studying in different departments of universities. The demographic features of the interviewed academics are presented in Table 1 and those of the interviewed students in Table 2.

We have abstained from giving detailed information on the participants to adhere to ethical rules in the study. While identifying the people to interview, their having studies on academic freedom, their having problems in terms of academic freedom, and their being experienced in the issue have been taken into consideration. The academics who participated in the study have been determined via the snowball sampling method, in which the process of sample formation starts with a single person and other participants are contacted after the interview with the first participant (Tanrı̈ver, 2011). This method is a sampling method that is not based on probability. While determining the academics to be interviewed, their knowledge about the subject and experiences at different universities were taken into consideration in the study. Table1 shows that four of the interviewed academics are female, seven of them are male, their titles are different, and they have different administrative duties.

Table 1. Demographic Features of Academics

\begin{tabular}{lll}
\hline Title & GenderDuty & Title \\
\hline Professor & Male & Member of the inter-university boards \\
Professor & Male & Director of institute \\
Associate Professor & Male & Vice dean \\
Associate Professor & Female & Head of department \\
Assistant Professor & Male & Head of department \\
Assistant Professor & Male & Head of department \\
Assistant Professor & Female & Assistant directorof institute \\
Assistant Professor & Male & Head of department \\
Lecturer & Male & Assistant director \\
Research Assistant & Female & - \\
Research Assistant & Female & - \\
\hline
\end{tabular}

The students who participated in the study were determined by using the random sampling method, which is a sampling method that is not based on probability. The main reason for choosing this method is that the students did not want to participate in the study, thinking that the issue is very sensitive. Thus, the process of data gathering, which had been problematic, made more functional.

According to Table 2, 152 of the participating students are female and 146 are male. They study in different departments. 
Table 2. Demographic Features of Students

\begin{tabular}{lll}
\hline Gender & Male & 152 \\
& Female & 146 \\
Department & Faculty of Education & 43 \\
& Faculty of Science and Letters & 42 \\
& Faculty of Engineering & 76 \\
& Faculty of Theology & 55 \\
& Faculty of Economic and Administrative Science & 44 \\
Total & Faculty of Tourism & 38 \\
& & 298 \\
\hline
\end{tabular}

\section{Validity and Reliability}

Resembling the internal validity of quantitative research, reliability in qualitative research is an element that allows others to observe that the participants directly incorporate their interpretations into the study (Thomas \& Magilvy, 2011).

While preparing the interview forms to provide the validity of the research, the related literature was reviewed in detail, and policies of academic freedom in higher education institutions were examined. To provide the convenience and content validity of the interview questions, which were prepared based on the literature, two academics who have a grasp of the topic were consulted. With the help of the advice from these experts, the interview questions were finalized. The interview form for the academics consisted of two sections and 7 and 8 questions on personal information and academic freedom, respectively. The interview form for the students also consisted of two sections and 4 and 7 questions.

We made an appointment with the academics to be interviewed; they were informed about the study in advance and were warned that the interview would be recorded. While scheduling an appointment with the academics to be interviewed, they were informed that their responses would be recorded, and they accepted this. The voice records acquired during the interview were transcribed directly on paper and the style of the academics was preserved during the transcription. In addition, the students whose opinions were sought were given an hour to complete the form.

Information- the title and gender of the academics, the frequency of the students who asserted the same opinions - about the participants from whom we obtained the data was coded next to the data in parenthesis during the presentation of the data in the findings. In this manner, the opinions and demographic features of the participant were correlated, and an attempt was made to provide the reliability of the study. 


\section{Results and Discussion}

According to the results of the content analyses applied, the views of academics and students concerning academic freedom were grouped into six different conceptual categories.

\section{Conceptual Categories about Academic Freedom}

In the conceptual categories about academic freedom presented, the titles and genders of the academics who expressed an opinion about the code and frequency of the students who shared the same opinion were indicated next to every code of the category. In doing so, the position of the students, who are an important part of academic freedom, was determined within it.

According to Table 3, the views of the academics and students concerning academic freedom were grouped into six different categories; (1) freedom in education, (2) freedom in research, (3) freedom of speech, (4) institutional freedom, (5) the importance of academic freedom, and (6) the protection of academic freedom.

Table 3. Six Different Conceptual Categories About Academic Freedom and The Features of These Categories

\begin{tabular}{ll}
\hline Categories & Features of Categories \\
& All students should be treated equally without any discrimination. (Prof. M.) \\
Students and academics should have the right to learn without any pressure. (Asso. \\
Prof. F.) \\
Students should have the right to change their adviser by justified causes. (Res. Asst. F.) \\
Academics should be able to have the right to lecture as much as they want. (Asst. \\
Prof. F.) \\
Students should be able to receive an education in the field they want at a university \\
they want. (f= 52) \\
Students should be able to improve themselves throughout their education life. (f=15) \\
Freedom in \\
Education \\
they want. (Lec. M) (f=3) \\
Academics should have the freedom to open a course, and students should be able to \\
have the freedom of take the course as they want. (f=18) \\
There should be freedom in the classroom atmosphere at the universities. (Res. Asst. F.) \\
All students should have equal rights to traineeship. (Prof. M.) \\
Students should be able to make their own decisions in their academic life. (f=14) \\
There should be an environment that can meet students' and academics' wants and \\
needs concerning their education in higher education institutions. (f=24) \\
Students should be able to reach the information they want whenever they want. (f=14)
\end{tabular}


Tablo 3. Continue

\begin{tabular}{ll}
\hline Categories & Features of Categories \\
\hline & $\begin{array}{l}\text { Academics and students should be able to express their ideas freely. (Asst. Prof. F.) } \\
(\mathrm{f}=73)\end{array}$ \\
Freedom of & $\begin{array}{l}\text { Academics should be able to feel comfortable in their relations with the administration. } \\
\text { (Assoc. Prof. } \mathrm{M})\end{array}$ \\
Speech & $\begin{array}{l}\text { Academics and students should not be able to be pressured due to their ideological } \\
\text { ideas. (Res. Asst F.), }(\mathrm{f}=16)\end{array}$
\end{tabular}

\begin{tabular}{ll}
\hline & Academics should be able to participation in administrative decision making (Asst. \\
& Prof. F.) \\
Intuitional & $\begin{array}{l}\text { The process of rector selection should be run fairly. (Assoc. Prof. M) } \\
\text { Freedom }\end{array}$ \\
& $\begin{array}{l}\text { Problems in the retrieval system should be removed. (Assoc. Prof. M) } \\
\text { Students should have a mechanism by which to express their complaints about } \\
\text { institution. (f=142) }\end{array}$ \\
\hline
\end{tabular}

Academic freedom is based on development and improvements. (Asst. Prof. F.)

Academic freedom prevents stagnation and nurtures originality. (Lec. M.), ( $\mathrm{f}=7$ )

Academic freedom is important in respect to economic and social relationships. (Asst.

Prof. M.). $\mathrm{f}=3$ )

Academic freedom is important so that academics are able to reveal their output freely and comfortably. (Lec. M.)

Importance of Academic freedom is important with regard to scientific improvement. (Prof. M.)

Academic Without academic freedom, academics would not be able to produce anything, and

Freedom scientific improvement would not be possible. (Res. Asst. F.), $(\mathrm{f}=14)$

Academic freedom is important because individuals should be able to work efficiently and succeed. $(\mathrm{f}=26)$

Academic freedom is important because individuals should be able to be trained to have freedom of mind and conscience. $(\mathrm{f}=9)$

Academic freedom is important because individuals should be able to gain selfconfidence and feel happy.(f=7)

Academics should be protectors of the freedoms that they possess. (Asst. Prof. M.)

There are serious problems concerning academic freedom that stemming from member

Protection of of the higher education council and the practices of rectors and the administration.

Academic (Asst. Prof. M.)

Freedom Academics are important protectors of academic freedom. (Res. Asst. F.)

The mental back ground should be constituted to be able to protect academic freedom. (Assoc. Prof. F)

Culture has an important effect on academic freedom. (Assoc. Prof. F)

\section{Academic Freedom in Education}

Freedom in education, which is under the scope of academic freedom (Karran, 2007), includes the freedoms that academics have in teaching their students. According to the results of the study, academics and students consider freedom in education to be an important part of academic freedom. According to Table 3, academics and students evaluate academic freedom in education within a framework of 14 key features. According to the participants, academic freedom in education is briefly as follows. 
- Academics and students should have the right of learn and teach without any pressure.

- Academics should have the right to open a course that they want, using the materials that they want in class.

- Students should have the right to take a course that they want.

- Students should have the right to make their own decisions about their academic lives and obtain an education in the department of a university that they want.

Academic freedomin education, which is an important part of academic freedom, encompasses the freedom that academics should have when teaching their students. Defining academic freedom, the participants generally spoke of academic freedom in education as seen in the following example.

'In the broadest sense, academic freedom is definedas academics' and students' rights to learn and teach as they want. Academic freedom is a basic and constitutive concept that comes to mind when talking about a modern university." (Asst. Prof. M.)

According to the results, the most important problems concerning academic freedom experienced in higher education institutions in education can be summarized as follows:

1) The course load on academics is too much.

2) The number of academics is very inadequate.

3) The in-class atmosphere is not free.

4) Classes are too crowded at universities.

Some views of academics related to the problems concerning academic freedom in education are presented below.

"Actually, an academic who teaches 20 hours a week can neither perform administrative affairs nor do research. We confront a negative situation because subordinates are asked to perform these tasks in Turkey."(Asst. Prof. F.)

"It is important that the in-class atmosphere is free. Nevertheless, that students don't criticize in classes indicates that we don't give this right to them and we don't teach criticizing. If students don't know how to criticize, this is because they aren't taught how to do so." (Asst. Prof. F.)

According to the results, the positive opinions of academics concerning academic freedom in education in higher education institutions are as follows:

1) The working hours of academics are flexible.

2) Academics can teach in the manner that they want.

3) Academics can use the materials that they want.

4) Academics can open a course that they want.

Some views of academics who expressed positive opinions concerning the issue are presented below.

"We confront a very flexible structure with regard to the working hours of academics in higher education institutions. Typically, nobody is interested in what time an academic starts the classand the manner in which he/she teaches in the classroom. An academic can open a course that he/she wants and can use any material that he/she wants in class."(Res. Asst. F) 
When we evaluate academic freedom with regards to the students, we typically confront academic freedom in education. A total of 163 of the 298 students participating in the study have responded with "No" to the question "Do you feel academically free?" Some of these 163 students have reported more than one reason for their negatives responses. Students have attributed their not feeling academically free to ten different reasons. The reasons why students do not feel free in academic terms are presented in Table 4.

Table 4. The Reasons Why Students Do Not Feel Academically Free

\begin{tabular}{ll}
\hline Reasons & f \\
\hline There is a transportation problem at universities. & 4 \\
There are negative effects of financial problems on academic life. & 6 \\
Student affairs officers have negative communication with students. & 13 \\
The classes are not efficient. & 15 \\
Students feel pressure at university due to their political opinions. & 16 \\
Faculty members do not have adequate communication with students. & 18 \\
The classrooms are very crowded, and the number of classrooms is inadequate. & 22 \\
Students cannot take the courses that they want from an academic who they want. & 22 \\
There is not an adequate educational environment at universities for students to improve & 32 \\
themselves. & 32 \\
The social activities at universities are inadequate. & 180 \\
Total &
\end{tabular}

When Table 4 is examined, it is observed that the most important reasons why students do not feel free at university are the following.

- "There is not an adequate educational environment at universities for students to improve themselves." ( $\mathrm{f}=32$ )

- "The social activities at universities are inadequate." $(\mathrm{f}=32)$

- "The classrooms are very crowded, and the number of classrooms is inadequate." ( $\mathrm{f}=22)$

- "Students cannot take the courses that they want from an academic who they want. " $(\mathrm{f}=22)$

\section{Academic Freedom in Research}

When the related literature is examined, it is observed that academics' freedoms in research can be ordered as follows: 1) academics' being free to conduct research on what they want in a manner befitting scientific and ethical principles without the fear of the displeasure of others and any pressure from the authorities; 2) academics' freedom to determine the scope of the topic to be studied and its linguistic expression befitting the scientific principles as they wish; 3) academics' being free to participate in any educational, social or professional organization, provided that it is legal; 4) academics' being free in their domestic and international travel with the aim of conducting research and providing educational improvement; and 5) academics' being free to publish the results of their studies without any pressure from the authorities (Eliot, 1907; Anderson, 1934; Hafstadter, 1955; Emerson \& Haber, 1964; Ashby \& Anderson, 1966; Dworking, 1979; Hook, 1971; Hamilton, 1998; Kahn \& Pavlich, 2000; Hamilton, 2002; Robinson, Moulton, \& College, 2002; Yalçın, 2002; Günay, 2004; Cain, 2007; Cole, 2009; Woodhouse, 2009; Balyer, 2011; Haberler, 2013).

The findings acquired in the study are parallel to the literature. The findings concerning freedom in research, which is an important dimension of academic freedom, indicate that academics confront problems concerning freedom in research more often than they experience problems concerning freedom in education. 
According to Table 3, academics tackle freedom in research under six key features. 1) Academics and students should be able to conduct research without any pressure. 2) Academics and students should be able to determine their research subject as they wish. 3) Academics should be able to publish their research results freely. 4) Academics should not confront bureaucratic obstacles when they conduct research. 5) Research opportunities at universities should be enriched. 6) The process of publishing a study should be fair. Some views of academics concerning freedom in research are presented below.

"Academic freedom is academics' and even students' being able to maintain activities of learning, teaching and conducting research comfortably without any pressure and restrictions."(Res. Asst. F.)

"If I am free in academic terms, I should be able to do research in a subject and field that I want. I shouldn't fear that somebody will withdraw my promotion as a result of my research. Unfortunately, academics experience this fear in Turkey." (Lec. M.)

Freedom in research, which is an important component for scientific progress, includes the entire process, from the scope of the subject of the research to the maintenance of the research and the publication of the results. In this process, academics are authorized to maintain their research without any pressure and limitations, abiding by research ethics, the necessities of science and the principles of intellectual ethics.

According to the findings, academics have some problems concerning freedom in research:

1) Overload of courses on academics obstructs them in conducting research as much as they want. Taking too many courses in addition to having administrative tasks, academics considered this condition a very important obstacle to freedom in research. On the other hand, the inadequate number of academic personnel at universities indirectly hinders freedom in research.

“New departments are opened at especially newly founded universities despite an inadequate number of faculty members. This raises the course load of academics. As a result, we finish the school year wearily and with difficulty. The overload of courses reduces our performance of both research and production." (Asst. Prof. F.)

2) Academics do not have sufficient freedom to conduct research on a subject they want. According to the findings, academics do not have enough freedom to conduct research on certain social issues. Some views of academics in this respect are presented below.

There are same concerns about freedom in research in Turkey. Academics are worried about problems such as will my research face a reaction from society, will my research results disturb somebody, considering the group of students and academics or society beyond the university, will I suffer as a result of my research?" (Asst. Prof. M.)

"As a doctoral student, I can't say that I have academic freedom given the circumstances in Turkey. There are various reasons for my feeling like this. I think that the first obstacle facing academic freedom is that the subjects of master's and doctoral studies are under the control of advisors. Unfortunately, one can't study what he/she wants as a subject. Researchers must study a subject that needs to be approved by their advisors or general trends of the field; sometimes, contrarian or original/innovative subjects face a reaction."(Lec. M.) 
3) The publishing process of the research is not sufficiently fair and takes too much time. Academics think that journals do not behave fairly during the publishing process of articles and that cronyism has an effect in this process. Some expressions supporting this view are presented below.

"The most important problem of restricting our freedom in research exists in the publishing process of the studies conducted in Turkey. Because the publishing policies of many journals depend cronyism. If you have a friend who is a journal editor, your paper is published in a very short period of time; otherwise, it takes a couple of years for your paper to be published." (Res. Asst. F.)

4) The density of bureaucratic work limits academics' freedom in research. According to the academics, the density of bureaucratic work is too much, and academics should tackle these works. On the other hand, opportunities to conduct research are very limited at newly founded universities. Hence, conducting research is very difficult within bureaucratic or administrative work and limited opportunities. An academic summarized this issue as below:
"Regarding academic freedom in research, it is an important obstacle that our studies are subject to several permissions while conducting research. Because the process of receiving permission is very problematic, we can't conduct our research as we want in other institutions that are related to the research. So, it is impossible to conduct research on every subject as we want and the way we wish." (Asst. Prof. M.)

5) Academics fear that, if their research results disturb somebody, obtaining an academic title may be hindered. According to the findings, academics argue that academic freedom increases when academic titles grow. Professors are freer than other academics because they do not have any reason to hold back.

"We can say that there are problems concerning academic freedom in Turkey. For example, while I was studying some subjects, my friends warned me that that subject was a bit problematic. They said, 'If you study that subject, you may have troubles before the associate professorship jury, and some academics may disturb you.' Unfortunately, we haven't overcome this problem."(Asst. Prof. M.)

According to the findings regarding freedom in research, the interviewed academics do not feel free enough in the field of the research. Solving problems such as overload of courses, bureaucratic work, and unfairness in the publishing processes will be an important step towards providing freedom in research. The academics make important suggestions about providing freedom in research;

- Academics should be able to conduct research without any pressure. (Res. Asst. F.)

- Students should be able to conduct research without any pressure. ( $\mathrm{f}=7$ )

- Academics should be able to determine their research subject as they wish. (Asst. Prof. M.)

- Students should be able to conduct research on a subject that they want. $(\mathrm{f}=7)$

- Academics should be able to publish their research results freely. (Asst. Prof. M.)

- Academics should not confront bureaucratic obstacles when conducting research. (Asst. Prof. F.)

- Research opportunities should be increased at universities. (Assoc. Prof. F.) 


\section{Freedom of Speech}

The views of academics and students concerning freedom of speech can be expressed under three key features.

- Academics and students should be able to express their ideas freely. (Asst. Prof. F.) (f=73)

- Academics should feel comfortable in their relations with the administration. (Asst. Prof. M.)

- Academics and students should not be exposed to pressure due to their ideological ideas. (Res. Asst. F.) (f=16).

Being able to maintain democratic principles depends on the accomplishment of other aims such as freedom of speech and publishing (Frimpong, 2004). In democratic societies, academic freedom is a logical extension of freedom of speech and freedom of the press (Moran, 1998). Therefore, it is a correct approach to consider freedom of speech an important dimension of academic freedom.

Academics need freedom of speech to maintain their professional activities, which make it possible to solve social problems and to be able to develop their professional behaviours. However, with regard to this issue, it is understood that the participating academics do not feel free enough. For the development of science, academics must have the right of speech without any pressure and the freedom to clearly express their opinions about the institution at which they work, and they should not be exposed to institutional censorship. The views of academics concerning freedom of speech are presented below.

"When talking about academic freedom, freedom of behaviour comes to my mind rather than freedom in research. Actually, freedom of behaviour indirectly influences academic studies. That is, academic freedom is academics' acting and behaving freely without considering their administrators' reactions in the institution." (Asst. Prof. M.)

According to the findings, academics do not have enough freedom whilemaintaining their academic studies and expressing their opinions about administrative issues. According to them, there is a restriction that stems from the problems of the system in obtaining an academic title and from the psychological pressure due to ideological power. In addition, it is observed that academics do not feel comfortable and speak freely when explaining the reason for this pressure during the interviews. The academics' opinions concerning the restrictions to their freedom of speech are presented below.

"Academic freedom is partially existent in Turkey. Actually, it depends on the academic title. The academic freedom of research assistants or assistant professors is lower than that of associate professors and professors. Research assistants have a lot of bureaucratic work, so their academic freedom is much more limited." (Assoc. Prof. F.)

“We can't express our thoughts and demands as they are. Actually, this is a mental limitation. The reason for this situation is the historical legacy and culture. The culture surrounding us and in which we grow, its beliefs and values influence our academic conversations and research. If an academic culture has been established somewhere, you can comfortably act, express your ideas andcritically approach the events there. We can't even completely provide critical thinking. This problem exists in both society and the academic community." (Asst. Prof. M.)

"Actually, I feel that my freedom of speech is restricted the most. Universities are multi-cultural structures. There should be people who know how to discuss every ideology and respect different views here. Especially these days, however, we don't have any chance to discuss our ideological, political or religious ideas. Indeed, there is a physiological pressure." (Res. Asst. F.) 
I don't think that there is an absolute academic freedom in Turkey. We can't explain what we think and the results we reach as they are. It seems that there is a natural boundary in academic freedomthat stems from our cultural background. In addition, there are points to be taken into consideration within the constitution. What our thoughts mean is important, it is part of the restrictions to academic freedom that, when there is a situation against the values, an investigation may be conducted against you." (Asst. Prof. M.)

When we examine thesubject with regard to the freedom of speech of students, we facea more serious scene. A total of 192 of 298 students who participated in the survey have stated that they cannot express their opinions on the lesson. Table 5 shows the reasons why students are being able to express their opinions.

Table 5. Reasons Why Students Are not Able to Express Their Opinions

\begin{tabular}{ll}
\hline Why can't you express your opinions in classes? & f \\
\hline I hesitate in case of being misunderstood. & 4 \\
I hesitate in case of receiving a negative reaction from my teachers. & 6 \\
I am concerned about being mocked by my friends. & 36 \\
No one is ready and content for criticism. & 34 \\
I am concerned about making pronunciation mistakes. & 10 \\
The inadequate field knowledge of the teachers. & 5 \\
\hline
\end{tabular}

According to Table 5, the most important reasons underlying students' not being able to express their opinions can be stated as follows: "their hesitation over being misunderstood" ( $\mathrm{f}=46$ ), "their hesitation over receiving a negative reaction from their teachers due to their opinions" ( $\mathrm{f}=36$ ), and "their concerns about being mocked by classmates due to their opinions" ( $\mathrm{f}=34$ ).

The findings obtained in the study are parallel to the findings of the study conducted by Molu, Gürsel, Kurt, Dinçer, \&Kıvılcım (2013, p. 6), who examine disciplinary investigations at universities. In this study, students' disciplinary investigations were examined. It is understood from the study that all of the disciplinary investigations into the students performed were initiated basically with regard to the students' actions concerning freedom of speech and becoming organized and that these investigations resulted in disciplinary punishments to the students. This result can be understood as another reason why students do not express themselves freely in class and are not able to share their problems with their professors and the university administration as they wish.

\section{Institutional Freedom}

Academics' views concerning institutional freedom generally focus on managerial freedom. In reality, higher education institutions should be institutions that can be internally managed without external intervention and that have institutional freedom. According to the data obtained, institutional freedom can be evaluated under four main headings.

1) Process of rectoral election: Academic freedom has been an institutional activity at universities that aim at democratic education or innovative discoveries (Lynch, 2003, p. 1065). Nevertheless, when the views of academics with regard to institutional freedom are examined, we face a pessimistic situation. According to the academics, problems concerning institutional freedom centre on the process of rectoral election and the malfunctioning within the system of obtaining academic titles. For the academics, being able to elect the university management or the department or faculty management freely is an important part of institutional freedom, which is a dimension of academic freedom. The views of the academics on this issue are as follows: 
"In Turkey, academics may experience serious troubles in participating in the administration." (Asst. Prof. M.)

"There are problems in the election of the management in higher education institutions. Academics always vote for a person who shares the same political views. In my opinion, academics, who have more freedom of thought than other professions, shouldn't be intensely connected with a political view. This system is good on paper, but we don't see this goodness in practice because people are offended by each other at the end of the elections and have conflicts. This has a negative effect on the organizational climate. This system seems to be liberal because he who gains the most votes democratically becomes the rector. Though it seems liberal, it isn't. Because academics can't vote for the candidates they determine. They vote for the candidate who shares the same political view." (Assoc. Prof. M.)

2) System of Obtaining Titles: The academics interviewed argue that another issue that harms institutional freedom is the malfunctioning in the system of obtaining titles. Some views of the academics concerning the problems in the system of obtaining titles are as follows:

"An important limitation of institutional freedom is the title system. The installation of our higher education system is good on paper. It is an inner promotional mechanism that depends on experience and production. A promotional mechanism may be necessary to prevent inertia and may drive academics to work more. This is the mechanical installation of the title system. However, it also has a version run by humans. The practices of being an associate professor or a professor function differently in Turkey. The election and assignment criteria are not clear enough. Everything depends on a commission. Many questions such as "How is this commission selected?", "How do the members of this commission act?", "How do they evaluate what academics have done?", "Are the files examined completely?" are without answers. That is, the qualities of that commission are what really affect the process. This may affect academic freedom. If the qualities of the commission are enhanced and negative aspects are eliminated, this may have positive consequences. There are malfunctions in the current system, there are people who are associate professors who don't deserve to be, and there are people who haven't become associate professors yet though they deserve to be, there are people who are professors who shouldn't be. Although these are my subjective ideas, there are many who think the same. It means there is a problem. In the USA, at universities such as Harvard, rectors are not elected; instead, they are assigned by a particular board. This system could be examined and implemented in Turkey."(Asst. Prof. M.)

"The titles have a major effect on academic freedom in Turkey. Professors can explain their thoughts more comfortably. Because they reached the highest title, they can, so they don't have any concerns. However, associate professors and assistant professor are less free due to the fear that they may not obtain an academic title. Actually, titles shouldn't play an important role in academic freedom." (Assoc. Prof. M.)

Views of the academics concerning institutional freedom may actually be considered a prescription for the solution to certain problems. For example, whether the above-mentioned American system of rectoral assignment is applicable in Turkey could be examined, which may help in solving the present problems concerning the issue. 
3) Newly founded universities: The academics' opinions concerning the newly founded universities are of high importance in terms of institutional freedom. That is, the academics who were interviewed state that academic freedom varies depending on the institution and, in addition to the qualitative problems experienced by the newly founded universities, there are problems concerning institutional freedom at these universities.
"The dramatic increase in the number of universities in Turkey recently has revived the issue of quality at universities. The fact that these newly founded universities have been established in the country has caused the academics who work there to feel less free in academic terms. Deficiencies such as a lack of adequate social and financial opportunities and an inadequate number of academics may be harming academic freedom."(Res. Asst. F.)
"There are some problems concerning academic freedom in Turkey, but I think academic freedom is better at older and long-established universities. I know this because I hear from fellow academics employed by those universities. Newly founded universities are more disadvantaged. This also because these universities are far from the centre."(Asst. Prof. M.)

4) Participating in decision-making processes. Academics who have administrative responsibilitiesdirector of institute, head of department, etc.-evaluate academic freedom from a different perspective. According to them, we face institutional freedom in the process of decision making. Currently, when there are many social and technological changes, institutional freedomisexposed to various restrictions. The cumbersome structure of the Higher Education Council (YÖK) and the density of bureaucratic issues negatively affect the decision-making process and harm academic freedom. On the other hand, academics consider that the existence of a supra-university council (YÖK) and its being subject to the Ministry of National Education are an obstacle to institutional freedom. Some academics who consider the existence of YÖK as a threat to academic freedom think that YÖK's being subject to the Ministry of National Education is a desperate situation in terms of academic freedom. Some views of the academics concerning this issue are presented below.

"In my opinion, universities are face to face with an obstacle at the point of autonomous decision-making. For, the permission of YÖK is needed for each innovation, change or decision-making process. This is harmful for the institutional freedom of universities. On the other hand, YÖK's being subject to the Ministry of National Education is an ankle bracelet fettered on the feet of universities." (Res. Asst. F.)

"Institutes at universities are more flexible than the departments. While performing tasks in the departments, you are the person who performs rather than the person who decides. At institutes, decision-making for public welfare is important. There, at institutes, it is the case that you must know for whom your decision becomes useful and for whom your decision becomes harmful. Here, you should make a decision for the benefit of both the institution and the individual. You shouldn't damage either the public or the individual, and in the case of a trial, you also shouldn't damage the institution. It is not easy to make such a decision. This is because institutes are research institutions and the time brings about quick changes. Thus, open-minded people who are able to adapt to changes should govern these institutions. However, higher education institutions have a cumbersome structure. It takes a long time to implement the regulations and the codes." (Asst. Prof. F.)

When we evaluate institutional freedom with regard to the students, we observe that 85 of the 298 students participating in the survey state that they have administrative problems at universities. 
They attribute this situation to "administrators' lack of communication with the students" $(\mathrm{f}=10)$ and "not valuing the ideas of the students" ( $\mathrm{f}=9$ ).

\section{Importance of Academic Freedom}

In situations in which the elements of academic freedom are masked, we face an ambiguous and entangled structure (Brown \& Kurland, 1993, p. 340). If academics or students are attacked due to their ideas, then, in the eyes of society, the value of the universities falls. Thus, academic freedom is highly important not only for academics but also for all of humanity. The reason is academic freedom is a very important factor in the development of humanity (Cole, 2005, p. 7). Academics who are aware of academic freedom consider the importance of academic freedom in five aspects:

1) Development and progress are based on academic freedom.

2) Academic freedom prevents stagnation and nurtures originality.

3) Academic freedom is important with regard to the economy and social relations.

4) For academics to produce genuinely and comfortably, academic freedomis important.

5) Academic freedom is needed due to academics' contribution to scientific development.

According to the academics, nothing can be produced and science cannot be generalized without academic freedom. Some views of the academics concerning the importance of academic freedom are presented below.

"Academic freedom is very important because development and progress are based on freedom. If you are not able to make universities free and there is a type of pressure there, the expression of thoughts, conducting research and publishing the findings are impeded there. As a result, where thoughts aren't produced, research isn't conducted, critical thinking doesn't exist and nothing is questioned, there will be retrogression and stagnation. Where there is critical thinking and the expression of thoughts, there is improvement. As a result, academic freedom is fundamental for development. If there is no academic freedom, the entire society is affected by this. That is, academic freedom is related to the economy, the social structure, even traffic accidents and forest fires. The damage caused by a lack of academic freedom spreads everywhere successively."(Asst. Prof. M.)

"Academic freedom is important to propose original things. Academic studies should contribute something new to the world of science rather than repeat the present knowledge. To be able to contribute something new, people should be a bit like outliers. The concern for conducting academic research in accordance with the present standards hinders innovative studies."(Lec. M.)

"Academic freedom is needed to contribute to scientific progress." (Prof. M.)

Academic freedom is needed to complete two main missions: providing a democratic education, which is a very serious issue, and enriching knowledge and new discoveries (Lynch, 2003, p. 1108). Academic freedom, which isat the heart of universities where knowledge and truth are sought, is the sine qua non of democratic states (Verlag, 1998). Academics who are aware of this agree on the importance of academic freedom.

When we evaluate the issue with regard to the students, 283 of the 298 students participating in the survey express that academic freedom is important. Students' views concerning why academic freedom is important are presented in Table 6. 
Table 6. Reasons Why Students Care about Academic Freedom

\begin{tabular}{ll}
\hline Why is academic freedom important? & $\mathbf{f}$ \\
\hline For individuals to be efficient and successful, academic freedomis important. & 26 \\
Academic freedom is important to grow individuals with a free mind and conscience. & 14 \\
Academic freedom is important for individual to be able to gain self-confidence and to feel happy. 9 \\
Academic freedom is important for spreading new and genuine ideas. & 7 \\
Academic freedom is important for student to feel comfortable in their academic life. & 7 \\
Solving social problems depends on academic freedom. & 3 \\
Academic freedom is important for the country to develop. & 3 \\
The world can change as a result of academic freedom. & 1 \\
\hline
\end{tabular}

According to Table 6, most of the students who state that academic freedom is important care about academic freedom "for individuals to be able to be efficient and successful" $(\mathrm{f}=26)$ and "for science to progress and generalize" $(\mathrm{f}=14)$.

\section{The Protection of Academic Freedom}

The freedom of academics, who are freer than other members of the society due to their intellectual richness and because they research, teach and learn, should be guaranteed so that they are able to conduct their scientific research (Cole, 2009). Thus, unless academic freedom can be protected at universities, academics feel as though they are slaves bound in chains (Lynch, 2003, p. 1063).

According to the academics interviewed, there are legal foundations for academic freedom in Turkey. An academic who has conducted several studies on this issue has expressed this situation as follows:

"The origin of the issue of academics freedom doesn't stem from the lack of laws in Turkey or the inadequacy of these laws. Actually, the laws in Turkey protect academics and students. Scientific autonomy is emphasized within the constitution; actually, this emphasis cannot be found in many countries. In Turkey, basic rights and freedom are present in the constitution; moreover, some freedoms concerning scientific autonomy and academics' freedom in research exist in Turkey. As a result, laws are already present, but the main problem is that they are not being enforced. There are serious problems in our country concerning this issue that stem from the practices of YÖK members, rectors and administrators. If the same legislation had been interpreted by different people in a more liberal manner, Turkey wouldn't have experienced the problems in the past. As a result, the largest responsibility for academic freedom is definitely with the academics. Academics should protect the freedom that they possess." (Asst. Prof. E.)

The findings obtained show various ways of protecting academic freedom. Academics should be the protectors of the freedomthat they have. The reason is academics are the most important protectors of academic freedom. Some views of the academics concerning the protection of academic freedom are presented below:

"In Turkey, we have serious problems concerning academic freedom. We can show chambers, stock markets or politics as the source of solutions to the problems of many professional institutions; we can also show the parliament as a source for the solution to some problems in society. However, in regard to academic freedom, an academic topic is mentioned. We are talking about an academic issue or a problem that stems from the ignorance of academics and their inability to found a tradition." (Asst. Prof. M.) 
In accordance with the findings of the research, it is possible to evaluate academics' views on the protection of academic freedom under three items:

1) Problems concerning academic freedom in our country that stem from the practices of YÖK members, rectors and administrators should be eliminated.

2) The necessary mental infrastructure should be built to able to protect academic freedom.

3) Protection of academic freedom depends on its transformation into a culture.

\section{Conclusion}

Although transferring knowledge to the students is perceived as the main function of academics, actually, the most important objective in a free education is to teach students how to acquire new information and how to apply this information in various fields. To guarantee this, academics need academic freedom while explaining the topics, including discussions and describing the real world in the classroom. To help students think critically about an issue or a problem, academics need to fully understand what the students' previous learning and beliefs about the topics are and compare, confirm, develop and interrelate the students' previous and present learning. On the other hand, students need academic freedom to develop their critical thinking, explain their ideas in a broad understanding and perspective, exploit opportunities and explain their opinions in front of everybody. In this process, both students and academics need academic freedom (AAUP, 2006). In this context, academic freedom encompasses the freedom of both academics and students with regard to education, research and speech (Searle, 1972, p. 170; UNESCO, 1998).

As the result of the findings of the study, it can be claimed that academics and students are afraid of negative reactions from the majority with regard to their religious or political ideas. Students cannot express their ideas during class due to the fear of being misunderstood or receiving a negative reaction. The same situation is observed within the academics' relations with the administration. Academics express that they have serious problems concerning academic freedom, and students express that they do not feel free enough at university.

Academics are afraid that the results of their studies may disturb others. The idea that academic freedom changes depending on the academic title and that political, religious and ideological opinions may prevent their promotion are an important obstacle to academics' being able to express their thoughts freely.

The inadequacy of the number of academics, the lack of transparency with in the publishing policies of journals, the malfunctioning of the title system and resentments following rectoral elections may be considered most important elements in the issue of academic freedom.

The recent quantitative increase in higher education institutions has led to some qualitative problems. These qualitative problems harbour certain threats with regard to the academic freedom of the academics and students at the newly founded universities. According to the academics, at the newly founded universities, there are problems concerning academic freedom that stem from the regions where they have been founded. A lack of educational (library, classroom, laboratory etc.) and social fields here has been expressed as the most important obstacle to both academics' and students' maintaining their academic lives freely. Although problems concerning academic freedom are based on cultural richness, some academics state that they may face serious problems when their studies are not appropriate for the culture of the society. 
It is possible to refer to the issue of academic freedom as a problem that stems from the ignorance of academics and their inability to found a tradition. The findings about the protection of academic freedom are parallel to those in the literature. According to Hamilton (1998, p. 159) and Summak (1998), the most important factor for the protection of academic freedom is that academics should fulfil their responsibilities to provide academic freedom. Doumani $(2005$, p. 23) and Poch (1994, p. 2), who express academic freedom as a black cloud over academics, argue that the best way to protect academic freedom is to fully understand the concept of academic freedom and its legal foundations.

According to the result of the study, academics are aware that they are the protectors of academic freedom, but it is not possible to talk about a determination that can solve this problem. The reason is academics and students prefer silence because they believe that the ideas that reflect their ideologies may disturb others. This situation appears as the reflection of ideological pressure on academic freedom at universities. Academics and students who internalize and defend the importance of academic freedom and who have self-confidence are needed for the pessimistic situation with regard to academic freedom to improve.

\section{Suggestions}

While determining the academics to be interviewed during the data-gathering process, it was understood that a limited number of academics had enough information about the issue. We wanted to increase the number of academics to be interviewed; however, wed is covered that academics were reluctant to express their ideas freely.

Academic freedom, an important requirement for a stress-free life, can only be conserved by academics. This awareness should be internalized by academics. For this reason, symposia and conferences on academic freedom should be held, and relevant studies should be diversified.

There has not been any study on the perceptions of academic freedom of academics employed by foundation universities. A comparative review of the academic freedom perceptions of academics employed by both state universities and foundation universities will fill an important gap in the literature.

There are very few resources about academic freedom in Turkish. For the issue to be better understood and to acquire detailed information on academic freedom in developed countries, the translation of resources in foreign languages into Turkish is of vital importance. 


\section{References}

American Association of University Professors (AAUP). (2006). 1940 Statement of principles on academic freedom and tenure with 1970 interpretive comments. Retrieved from http://www.aaup.org/file/1940\%20Statement.pdf

Anderson, W. (1934). Academic freedom. Australasian Journal of Psychology and Philosophy, 12(2), 138142.

Ashby, E., \& Anderson, M. (1966). Universities: British, Indian, African. The Journal of Modern African Studie, 4(4), 556.

Balyer, A. (2011). Academic freedom: Perceptions of academics in Turkey. Eğitim ve Bilim, 36(112), 138148.

Borhan, C. (2009). Exploring the concepts of academic freedom and institutional autonomy- A case study of the faculty of political science at the University of Suleimaniyah (Master's thesis). The University of Bergen.

Brown, R. S., \& Kurland J. E. (1993). Academic tenure and academic freedom. In freedom and tenure in the academy. Durham, NC: Duke University Press.

Cain, T. R. (2007). For education and employment: The American federation of teachers and academic freedom, 1926-1941. Perspectives on The History of Higher Education, 26, 67-102.

Cole, J. R. (2005). Academic freedom under fire (pp. 1-13). Coloumbiya University: Doedalus Spring.

Cole, J. R. (2009). Defending academic freedom and free inquiry. Social Research, 76(3), 811-844.

Diekema, A. J. (2000). Academic freedom \& Christian scholarship. USA: Wm. B. Eerdmans.

Dinler, V. (2013). Akademik özgürlüğün sınırı üzerine sorular. Muhafazakar Düşünce, 9(35), 239-291.

Doğan, D. (2015). Accountability and academic freedom in the higher education instituates of Turkey (Doctoral dissertation). EskişehirOsmangazi University, Institute of Educational Sciences, Eskişehir.

Doumani, B. (2005). Academic freedom post-9/11. ISIM Review, 15(1), 22-23.

Dworking, R. (1979). Academic freedom. Philosophical Papers, 8(1), 1-10. doi:10.1080/05568647909506491

Eliot, C. W. (1907). Academic freedom. Science, 6(653), 1-12. Retrieved from http://www.jstor.org/stable/1633598

Emerson, T. I., \& Haber, D. (1964). Academic freedom of the faculty member as a citizen. In H. W. Baade (Ed.), Academic freedom: The scholar's place in modern society (pp. 95-142). Dobbs Ferry, NY: Oceania Publications.

Eser, Z., \& Birkan, İ. (2005). Marketing education in Turkey. Journal of Teaching in International Business, 16(2), 75-101. doi:10.1300/J066v16n02_05

Frimpong, S. O. (2004). Adolecents' perception of and attitude towards sex education: A case study of senior secondary schools in the Kumasi metropolis (Master's thesis). University of Cape Coast, Ghana.

Gerstmann, E., \& Streb, M. J. (2006). Academic freedom at the dawn of a new century. How terrorism, goverment sent culture wars impact free speech. California: Standford University Press.

Günay, D. (2004). Üniversitelerin neliği, akademik özgürlük ve üniversite özerkliği. Paper presented at the International Congress on Higher Education, İstanbul.

Haberler, Z. J. (2013). Liberty but not license: Publicity, academic freedom, and the professionalization of the professoriate, 1890-1929 (Doctoral dissertation). University of California Riverside, California.

Hafstadter, R. (1955). Academic freedom in the age of the college. Columbia: Columbia Universty Press.

Hamilton, N. (1998). Zealotry and academic freedom. New Jersey: Transaction.

Hamilton, N. W. (2002). Academic ethics: Problems and materials on professional conduct and shared governed. Washington: Praeger. 
Hayes, D. (2014). Free speech needs to be heard.Retrieved October 21, 2014, from http://www.thefreesociety.org/Articles/Comment/free-speech-needs-to-be-heard

Hook, S. (1971). Academic freedom and academic anarchy. New York: Cowles Book Company.

Kahn, S. E., \& Pavlich, D. (2000). Academic freedom and the inclusive university. Canada: UBC Press.

Karran, T. (2007). Academic freedom in Europe: A preliminary comparative analysis. Higher Education Policy, 20(3), 289-313.

Kennedy, D. (1998). Academic duty. London: Harvard University Press.

Lynch R. G. (2003). Pawns of the State or priests of democracy? Analyzing professors' academic freedom rights within the state's managerial realm. California Law Review, 91(4), 1061-1108. Retrieved from http://www.jstor.org/stable/3481409

Merriam, S. B. (2013). Quantitative research (S.Turan, Trans.). Ankara: Nobel.

Moran, G. (1998). Silencing scientists and scholars in other fields: Power, paradigm controls, peer review, and scholarly communication. London: Ablex Publishing Corporation.

Molu, B., Gürsel, E., Kurt, G., Dinçer, H., \& Kıvılcım, Z. (2013). Üniversitelerde disiplin soruşturmaları: Öğrencilerin ifade ve örgütlenme özgürlü̆̆̈̈ çerçevesinde bir değerlendirme. İstanbul: Levha.

Özipek, B.B. (2001). The meaning and necessity of academic freedom. Journal of Liberal Thought, 185195

Poch, R. K. (1994). Academic freedom in American higher education: Rights, responsibilities and limitations. Retrieved from ERIC Databases (ED366262).

Horn, M. (1999). Academicfreedom in Canada: A history. University of Toronto Press. Retrieved from http://www.jstor.org/stable/10.3138/9781442670570

Robinson, G., Moulton, J., \& College, S. (2002). Academic freedom. In Encyclopedia of Ethics. Garland Publishing.

Roche, G. C. (1969). Academic freedom for what?. Education in America, 19, 1-13.

Searle, J. R. (1972). The campus war: A sympathetic look at the university in agony. Penguin Books. Retrieved June 16, 2014 from https://www.questia.com/free-trial

Seggie, F. N., \& Gökbel, V. (2015). From past the present academic freedom in Turkey. Ankara: SETA.

Summak, S. M. (1998). Academic human rights and freedoms in Turkey. The Educational Forum, 62(1), 32-39. doi:10.1080/00131729708982678

Tanrı̈̈ver, A. (2011). Bilimsel araştırma yöntemleri. Anraka: Anı Publishing.

Thomas, E., \& Magilvy, J. K. (2011). Qualitative rigor or research validity in qualitative research. Journal for Specialists in Pediatric Nursing, 16(2), 151-155.

UNESCO. (1997). Records of the general conference. In United Nations Educational, Scientific and Cultural Organization. Paris: UNESCO.

UNESCO. (1998). Social responsibility and academic freedom and autonomy, international association of universities. Retrieved April 15, 2014 from http://www.unesco.org/iau/tfaf_working_doc.html

Verlag, H. U. (1998). Academic freedom. Academic symposia. Munich: Tel Aviv Universty.

Weiker, W. F. (1962). Academic freedom and problems of higher education in Turkey. Middle East Journal, 3(16), 279-294.

Woodhouse, H. (2009). Selling out: Academic freedom and the corporate market. McGill-Queen's University Press. Retrieved from http://www.jstor.org/stable/j.ctt24hp28

Yalçın, C. (2002). A study on academic freedom. Eurasian Journal of Educational Research, 7, 1-15. 